\section{CrossMark} $\leftarrow$ click for updates

Cite this: J. Mater. Chem. B, 2016, 4,6428

\title{
Influences of mesoporous magnesium silicate on the hydrophilicity, degradability, mineralization and primary cell response to a wheat protein based biocomposite
}

\author{
Shipeng Feng, ${ }^{a}$ Jianyou $\mathrm{Li}_{1} \uparrow^{\mathrm{b}}$ Xuesheng Jiang, ${ }^{\mathrm{b}}$ Xiongfeng Li, ${ }^{\mathrm{b}}$ Yongkang Pan, ${ }^{\mathrm{a}}$ \\ Liming Zhao, ${ }^{a}$ Aldo R. Boccaccini, ${ }^{c}$ Kai Zheng, ${ }^{c}$ Lili Yang ${ }^{* d}$ and Jie Wei*a
}

\begin{abstract}
A novel bioactive composite based on wheat protein (WP) and mesoporous magnesium silicate (m-MS) with a high specific surface area is presented in this study for potential bone tissue regeneration. Wheat protein (WP) is a type of a biodegradable natural polymer material. The m-MS was prepared by the sol-gel technique, which was incorporated into WP to fabricate m-MS/WP composites. The increasing amount of $m-M S$ improved the surface hydrophilicity of $m-M S / W P$ composites. The results showed that the degradation ratio of the $\mathrm{m}$-MS/WP composites increased with an increase in the $\mathrm{m}$-MS content after it was soaked in a Tris- $\mathrm{HCl}$ solution for 12 weeks. Moreover, the m-MS/WP composites with 40 wt\% $\mathrm{m}$-MS content (WP40) were able to maintain a suitable $\mathrm{pH}$ value over a prolonged soaking time, which might be dependent on the content of the m-MS. The WP40 showed a good apatite formation ability after it was soaked in simulated body fluid (SBF) for 7 days, indicating good bioactivity. Moreover, the WP40 with cytocompatibility stimulated the attachment, proliferation and differentiation of MC3T3-E1 osteoblast cells. Briefly, the results indicated that WP40 had good bioactivity, degradability, cytocompatibility and osteogenesis and might be a new biomaterial for bone regeneration.
\end{abstract}

Received 12th June 2016

Accepted 9th September 2016

DOI: $10.1039 / c 6 t b 01449 f$

www.rsc.org/MaterialsB

\section{Introduction}

Natural polymers, which come from common agricultural products, for example plant protein and plant starch and etc., have gradually attracted attention as biodegradable polymer materials because of dwindling petroleum resources. ${ }^{1,2}$ Currently, natural polymers are widely used in the field of regenerative medicine, such as bone regeneration materials and implantable cardiovascular devices, because of their biodegradability and biocompatibility. ${ }^{3,4}$ In addition, during the process of promoting bone repair, natural polymers are involved in the repair of damaged tissues and tissue regeneration. ${ }^{5}$

\footnotetext{
${ }^{a}$ Key Laboratory for Ultrafine Materials of Ministry of Education and The State Key Laboratory of Bioreactor Engineering, East China University of Science and Technology, Shanghai 200237, China. E-mail: jiewei7860@sina.com; Fax: +86-21-64252745; Tel: +86-21-64252745

${ }^{b}$ Orthopedics Department, Huzhou Central Hospital, 198 Hongqi Road, Huzhou 313000, China

${ }^{c}$ Institute of Biomaterials, Department of Materials Science and Engineering, University of Erlangen-Nuremberg, Cauerstrasse 6, 91058 Erlangen, Germany

${ }^{d}$ Department of Orthopaedic Surgery, Changzheng Hospital, The Second Military Medical University, Shanghai 200003, China. E-mail: orthoyang@sina.com; Fax: +86-21-64252745; Tel: +86-21-64252745

$\dagger$ Jianyou Li is co-first author.
}

Wheat protein (WP), derived from the second largest cereal crop, is one of the most promising natural polymer materials. ${ }^{6}$ WP is composed of four main parts, albumins, globulins, gliadins and glutenins. ${ }^{7}$ These protein subunits are linked together by disulfide and hydrogen bonds between cysteine residues to form very large protein polymers. ${ }^{8,9}$ In addition, the types of amino acid in WP are relatively abundant (e.g., glutamate, glycine, proline, serine), and they are similar to those in collagen protein in natural bone. ${ }^{10-12}$ Therefore, WP can provide enough nutrients for bone repair because of its abundant nutrition and good quality.

Mesoporous materials with pore sizes ranging from 2-50 nm have been widely used in biomaterials, catalysis, drug loading, gas storage, and electrode materials. ${ }^{13}$ During the last few decades, the application of mesoporous materials in bone tissue has increased rapidly owing to the unique characteristics including their uniform and tunable pore size distribution, high specific surface area, and high pore volume encompassing several desirable characteristics. ${ }^{14,15}$ Shi et al. pointed out the materials were more prone to accelerate the deposition kinetics with a higher the specific surface area and a higher pore volume of the materials, thereby improving the bioactivity and biocompatibility of the materials. ${ }^{16}$

$\mathrm{Mg}$ ions undoubtedly play an important role in the health of the human body, and this is mainly related to the mineralization of calcined tissues and indirectly influences mineral metabolism. ${ }^{17}$ 
In recent years, magnesium-based biomaterials for hard tissue repair have received attention, for example biodegradable magnesium alloys, ${ }^{18-20}$ magnesium-containing bioactive glasses ${ }^{21}$ and $\mathrm{Mg}$-substituted phosphate bone cements ${ }^{22}$ and so on. Magnesium silicate (MS) bioceramics have gradually been used in tissue regeneration because of the controllable degradation rate, good mechanical properties, significant bone-like apatite formation ability and even excellent bioactivity. ${ }^{23}$ Additionally, the osteogenesis property of MS has made it an outstanding candidate for bone regeneration. ${ }^{24}$ Niu et al. revealed that there was no cytotoxicity from MS bioceramics against the osteogenic cell in the vitro experiments because the existence of the apatite layer makes the material perfectly attach to bone tissues. ${ }^{25}$

Currently, reports on wheat protein-based composites for bone regeneration biomaterials are still limited. Moreover, no previous studies have reported on the addition of mesoporous magnesium silicate (m-MS) into wheat protein for bone repair and regeneration application. In this study, the novel composites of mesoporous magnesium silicate and wheat protein were developed by incorporating m-MS into wheat protein, and the influences of m-MS content on the properties of the m-MS/WP composites were investigated. The degradability and bioactivity of the m-MS/WP composites were assessed by in vitro degradation and mineralization experiments. Additionally, cell attachment, proliferation and differentiation experiments were used to further demonstrate the cytocompatibility of m-MS/WP composites.

\section{Experimental}

\subsection{Preparation and characterization of $\mathrm{m}-\mathrm{MS} / \mathrm{WP}$ composites}

Amorphous mesoporous magnesium silicate was synthesized by the sol-gel technique using the triblock copolymer of poly(ethylene glycol)-block-poly(propylene glycol) (P123, Sigma Aldrich Chemistry, Shanghai) as the structure-directing agent. In this strategy, the incorporation of P123 was critical for obtaining well-ordered structures. Briefly, 6 g P123 and $20.04 \mathrm{~mL}$ $\mathrm{HCl}$ were dissolved in $129.96 \mathrm{~mL}$ of deionized water with stirring for $6 \mathrm{~h}$ until the solution was clarified. After that, $9.12 \mathrm{~g}$ tetraethyl orthosilicate (TEOS) and $9.6 \mathrm{~g} \mathrm{Mg}\left(\mathrm{NO}_{3}\right)_{2} \cdot 6 \mathrm{H}_{2} \mathrm{O}$ were added into the solution, and during this process, the temperature was kept at $50{ }^{\circ} \mathrm{C}$. After vigorous stirring for $5 \mathrm{~h}$, the milk-like solution was placed at $80{ }^{\circ} \mathrm{C}$ for $72 \mathrm{~h}$. The products were collected by filtration and washed by deionized water and ethanol. Finally the collected powders were dried at $90{ }^{\circ} \mathrm{C}$ and sintered at $600{ }^{\circ} \mathrm{C}$ for $6 \mathrm{~h}$ to remove the remaining $\mathrm{P} 123$. All the chemicals were obtained from Shanghai Lingfeng Chemical Regent Co., Ltd.

The morphology and composition of m-MS were characterized by scanning electron microscopy (SEM; S-3400N; Hitachi, Japan), transmission electron microscopy (TEM, JEM-2010, JEOL Ltd, Japan), energy dispersive spectrometry (EDS, JEOL-6360LV, Japan), and X-ray diffraction (XRD, D/max 2550 VB/PC, Rigaku Co., Japan). Additionally, $\mathrm{N}_{2}$ adsorption-desorption isotherms, the pore diameter distribution, and surface areas/pore volumes were determined by Brunauer-Emmett-Teller (BET, Tristar 3000, Micromeritics, USA).
The wheat protein (WP) was purchased from Japan Tokyo Chemical Industry Co., Ltd. (TCI), and the m-MS/WP composites with $0 \mathrm{wt} \%, 20 \mathrm{wt} \%$ and $40 \mathrm{wt} \% \mathrm{~m}-\mathrm{MS}$ content (WP0, WP20, WP40) were prepared by compression method. In brief, m-MS and WP powders were uniformly mixed in a certain percentage and added to the mold. Disc-shaped samples $(\Phi 12 \times 2 \mathrm{~mm})$ were consolidated under a pressure of $2 \mathrm{MPa}$ for $3 \mathrm{~min}$. The composition and structure of the samples were characterized by Fourier transform infrared spectroscopy (FTIR, Thermo Nicolet 6700 , Waltham, MA, USA) and X-ray diffraction using the D/max 2550VB/PC diffractometer (Rigaku, Tokyo, Japan) with a scan range from $10^{\circ}$ to $80^{\circ}$. The hydrophilic properties of the samples with different m-MS contents were determined by water contact angles.

\subsection{In vitro degradability of $\mathrm{m}-\mathrm{MS} / \mathrm{WP}$ in a Tris-HCl solution}

To study the degradability of the composites with $0 \mathrm{wt} \%$, $20 \mathrm{wt} \%$ and $40 \mathrm{wt} \% \mathrm{~m}-\mathrm{MS}$ content $(\Phi 12 \times 2 \mathrm{~mm})$, the weight loss ratio and $\mathrm{pH}$ change of the solution after the samples were soaked for different times were monitored with an electronic balance and pH meter (PHS-3C, INESA, Shanghai Instrument), respectively.

The samples were placed in separate polypropylene vials and incubated in a Tris- $\mathrm{HCl}$ solution $(\mathrm{pH}=7.4)$ at $37{ }^{\circ} \mathrm{C}$ for 12 weeks. The solution volume/the specimen weight ratio was $20 \mathrm{~mL} \mathrm{~g}^{-1}$. The Tris-HCl solution was changed once a week. The samples were taken out at different time points $(1,2,3,4,5,7,8$, 10 and 12 weeks) from the solution and dried at $50{ }^{\circ} \mathrm{C}$ in an oven.

The percentage of weight loss was determined using the following equation:

$$
\text { Weight loss }(\%)=\left(W_{0}-W_{t}\right) / W_{0} \times 100 \%
$$

where $W_{0}$ and $W_{t}$ represent the initial weight of the samples and the weight of the samples after immersion in Tris- $\mathrm{HCl}$ solution for different time periods, respectively.

During the 12 weeks of immersion, the $\mathrm{pH}$ change of the solution after the samples soaked for different times was measured at different time points $(1,2,3,4,5,7,8,10$ and 12 weeks). Tris- $\mathrm{HCl}$ was not replaced during the $\mathrm{pH}$ measurements.

The surface morphology of the samples after immersion in Tris-HCl for 3 weeks was determined by scanning electron microscopy (SEM; S-3400N; Hitachi, Japan).

\subsection{In vitro bioactivity of $\mathrm{m}-\mathrm{MS} / \mathrm{WP}$ in simulated body fluid}

In vitro bioactivity of the composites was determined by soaking the samples in simulated body fluid ( $\mathrm{SBF}, \mathrm{pH}=7.4$ ) at $37^{\circ} \mathrm{C}$ for up to 7 days. The solution volume/the specimen weight ratio was $20 \mathrm{~mL} \mathrm{~g}^{-1}$. After soaking for different times, the samples were washed by deionized water and then dried in an oven at $50{ }^{\circ} \mathrm{C}$ for $24 \mathrm{~h}$. The surface morphology of the samples before and after immersion in SBF were determined by scanning electron microscopy (SEM; S-3400N; Hitachi, Japan), and the surface composition was determined by X-ray diffraction (XRD, D/max 2550 VB/PC, Rigaku Co., Japan) and energy dispersive spectroscopy (EDS; Falcon, USA). The ion concentrations ( $\mathrm{Si}, \mathrm{Ca}, \mathrm{Mg}, \mathrm{P}$ ions) in the $\mathrm{SBF}$ were determined by inductively coupled plasma atomic emission spectroscopy 
(ICP-AES; IRIS 1000; Thermo Elemental, USA) after the WP40 soaked in SBF for 1, 3, 5, 7 and 14 days.

\subsection{Cell attachment}

Interactions between the osteoblasts and the composites were investigated using the mouse osteoblast cell line MC3T3-E1. The three group samples (WP0, WP20 and WP40) were placed in a 24 -well plate, which was sterilized in $100 \%$ ethanol for $1 \mathrm{~h}$ and then UV radiated for $1 \mathrm{~h}$. The MC3T3-E1 cells were seeded on these substrates at a density of $2 \times 10^{4}$ cells per well and incubated at $37^{\circ} \mathrm{C}$ in an atmosphere of $5 \% \mathrm{CO}_{2}$ and $95 \%$ air for 3 days. Then, the specimens were washed 3 times with phosphate buffered saline (PBS), and the cells on the surfaces of the three kinds of samples were fixed with $4 \%$ glutaraldehyde for 2 h. Finally, the cell-seeded samples were stained with fluorescein isothiocyanate (FITC) and $4^{\prime}, 6^{\prime}$-diamidino-2-phenylindole (DAPI) for 40 minutes and 5 minutes, respectively. The morphology of the cells on the samples was observed by confocal laser scanning microscopy (CLSM; Hitachi).

\subsection{Cell proliferation}

Cell proliferation was investigated by the methylthiazol tetrazolium test (MTT) after 1, 3, and 5 days of culture. Briefly, three group samples (WP0, WP20 and WP40) were placed in a 24-well plate. The cell suspension $(1 \mathrm{~mL})$ at a cell density of $5 \times 10^{3}$ viable cells was seeded on the samples and then kept at $37{ }^{\circ} \mathrm{C}$ in a humidified incubator with $5 \% \mathrm{CO}_{2}$. After the specimens were placed into new plates, $0.1 \mathrm{~mL}$ of the MTT solution $\left(0.5 \mathrm{mg} \mathrm{mL}^{-1}\right)$ was added, and the samples were incubated at $37{ }^{\circ} \mathrm{C}$. After incubation, $50 \mu \mathrm{L}$ dimethyl sulfoxide (DMSO, Sinopharm, Shanghai, China) was added per well to dissolve the purple formazan, and this was mixed thoroughly by pipetting the solution. The solution was then incubated at $37{ }^{\circ} \mathrm{C}$ for $10 \mathrm{~min}$. The optical density (O.D.) was measured at $570 \mathrm{~nm}$ using an automated plate reader (Synergy HT Multi-detection Microplate).

\subsection{Alkaline phosphatase activity}

Alkaline phosphatase (ALP) activity was used to analyse the boneforming ability of MC3T3-E1 cells at a relatively early stage $(7,10$, and 14 days of culture) on the samples. A total of $2.5 \times 10^{4}$ of cells were seeded on each specimen (WP0, WP20 and WP40) in the 24-well plates and was then cultured at $37{ }^{\circ} \mathrm{C}$ in an atmosphere of $100 \%$ humidity with $5 \% \mathrm{CO}_{2}$. In this process, after aspirating the culture media in 24-well plates, cell lysate was obtained by adding $200 \mu \mathrm{L}$ $1 \%$ Nonidet P-40 (NP-40) for $1 \mathrm{~h}$. Then, $50 \mu \mathrm{L}$ of the supernatant was added into the 96-well plates, which followed by adding $\rho$-nitrophenyphosphate (Sigma, Singapore) substrate solution composed of $0.1 \mathrm{~mol} \mathrm{~L}^{-1}$ glycine and $1 \mathrm{mmol} \mathrm{L}{ }^{-1} \mathrm{MgCl}_{2} \cdot 6 \mathrm{H}_{2} \mathrm{O}$. Finally, after incubating for $1 \mathrm{~h}$ at $37^{\circ} \mathrm{C}$, the reaction was arrested by adding $100 \mu \mathrm{L}$ of a $2 \mathrm{M} \mathrm{NaOH}$ solution. The colored product of ALP activity was measured at $405 \mathrm{~nm}$ using a microplate reader.

\subsection{Statistical analysis}

A minimum of five samples was tested per group for physical and chemical properties, and six parallel samples per group for the cell experiments. $p<0.05$ was considered statistically significant. All quantitative data were analysed with Origin pro8.0 and expressed as the mean \pm standard deviation ( $\mathbf{M} \pm$ s.d.).

\section{Results and discussion}

\subsection{Characterization of $\mathrm{m}-\mathrm{MS}$}

Fig. 1a shows an SEM image of m-MS, indicating that m-MS powders had a regular worm-like morphology (2-3 $\mu \mathrm{m}$ in length) with a smooth surface. From the TEM images (Fig. 1b), it can be seen that m-MS has highly ordered mesoporous channels and uniform pore size. EDS results for m-MS are shown in Fig. 1c, and $\mathrm{Mg}$ and $\mathrm{Si}$ were found in the samples. The small-angle XRD was applied to explore the pore structure of m-MS (Fig. 1d), and the m-MS exhibited a hexagonally ordered mesoporous structure with (100), (110) and (200) reflections of p6mm symmetry. From the $\mathrm{N}_{2}$ adsorption-desorption isotherms (Fig. 1e), the irreversible type IV adsorption-desorption isotherms with a $\mathrm{H} 1$ hysteresis loop indicated their mesoporous channels and narrow pore size distributions. The BET results (Fig. 1f) revealed that the specific surface area of m-MS was $395.3 \mathrm{~m}^{2} \mathrm{~g}^{-1}$, the pore volume was $0.53 \mathrm{~cm}^{3} \mathrm{~g}^{-1}$, and the pore diameter was $6.4 \mathrm{~nm}$.

\subsection{Characterization of $\mathbf{m}-\mathrm{MS} / \mathrm{WP}$ composites}

Fig. 2a shows the FTIR absorption spectra of m-MS, WP0, WP20 and WP40. The peaks at $1660 \mathrm{~cm}^{-1}$ and $1529 \mathrm{~cm}^{-1}$ were from typical $\mathrm{N}-\mathrm{H}$ bending vibrations, while the broad absorption band at $3300-3500 \mathrm{~cm}^{-1}$ was the $\mathrm{N}-\mathrm{H}$ stretching vibration. All the $\mathrm{N}-\mathrm{H}$ peaks above can be found in the three groups of the m-MS/WP composites from the rich amino acid in wheat protein, and with the addition of $\mathrm{m}-\mathrm{MS}$, the $\mathrm{N}-\mathrm{H}$ characteristic peaks gradually weakened. The peaks at $1080 \mathrm{~cm}^{-1}$ and $802 \mathrm{~cm}^{-1}$ were attributed to the $\mathrm{Si}-\mathrm{O}-\mathrm{Si}$ asymmetric stretching vibration and symmetric stretching vibration, respectively. $\mathrm{Si}-\mathrm{O}-\mathrm{Si}$ characteristic peaks were found in the WP20 and WP40 composites, which implied WP and m-MS were uniformly mixed.

Fig. 2b shows the XRD spectra of m-MS, WP0, WP20 and WP40. Wheat protein has a broad peak at $2 \theta=20^{\circ}$, which is due to its amorphous structure. The characteristic peak of m-MS is a broad peak at about $2 \theta=24^{\circ}$, which is a typical structure for amorphous silicate materials, and the peak at $2 \theta=20^{\circ}$ shifted to a higher angle peak with the increasing amount of m-MS. The results showed that WP and m-MS were mixed uniformly, and there were no crystalline phases in the composites.

The hydrophilicity of the m-MS/WP composites with $0 \mathrm{wt} \%$, $20 \mathrm{wt} \%$ and $40 \mathrm{wt} \% \mathrm{~m}-\mathrm{MS}$ content was measured by a static contact angle measurement system (Fig. 3). It was observed that WP0 had a water contact angle of $75.8^{\circ}$. Moreover, the water contact angles fell sharply to $59.8^{\circ}$ and $55.2^{\circ}$ for WP20 and WP40, respectively. Hence, the surface hydrophilicity of the composites was significantly enhanced by the increase of the m-MS content. Previous studies revealed that WP exhibited a good water contact angle, which is due to polar amino acids (hydrophilic). ${ }^{26}$ In this study, it is found that the presence of an increasing amount of m-MS tended to favor the spreading of the water drop over the composite surface, resulting in a 

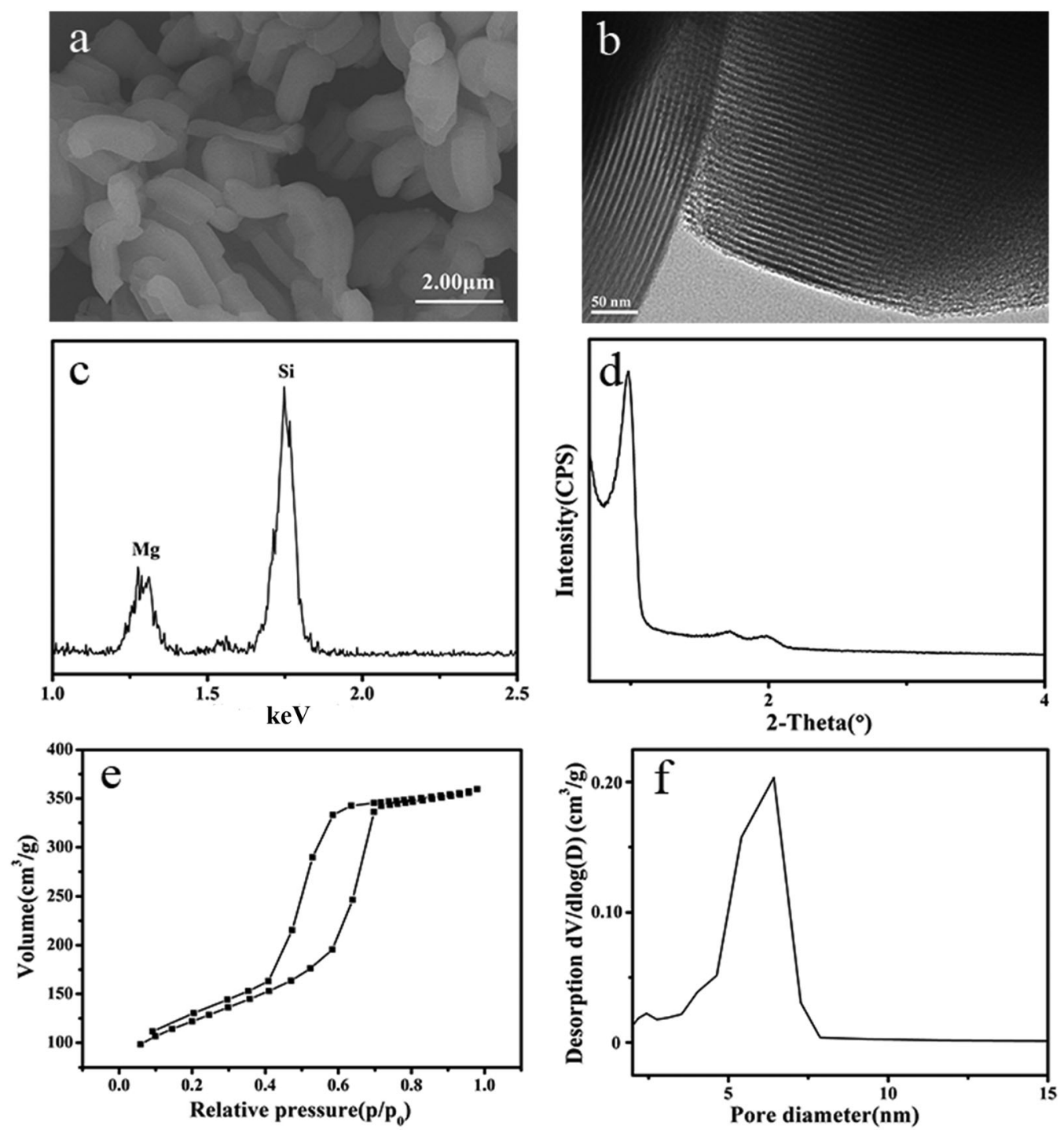

Fig. 1 SEM image (a), TEM image (b), EDS (c), small-angle XRD (d), $\mathrm{N}_{2}$ adsorption-desorption isotherms (e), and the pore diameter distribution (f) of $m$-MS.

reduction in the water contact angle. Improved surface hydrophilicity promoted interactions between the materials and cells, which facilitated cell adhesion, proliferation and even bone forming ability. ${ }^{27,28}$

\subsection{Degradability of $\mathrm{m}-\mathrm{MS} / \mathrm{WP}$ composites}

Fig. 4 shows SEM images of the surface morphology of WP0, WP20 and WP40 after immersion in Tris-HCl for 3 weeks. SEM images show the surface of WP0 was relatively smooth, and cracks appeared over the prolonged soaking time (Fig. 4a). On the contrary, WP20 and WP40 prepared by incorporating m-MS into WP had erosion morphology, which indicated WP20 and WP40 can be degraded in Tris-HCl (Fig. $4 \mathrm{~b}$ and c). Furthermore, the surface of WP40 became rougher with some deep ditches (Fig. 4c).

The degradability of the m-MS/WP composites was measured by monitoring the weight loss of the samples and $\mathrm{pH}$ changes of the solution after the samples were soaked in Tris- $\mathrm{HCl}$ for different times (Fig. 5). Fig. 5a presents the weight loss of the $\mathrm{m}-\mathrm{MS} / \mathrm{WP}$ composites. It can be found that over 12 weeks, all of the composites with different m-MS content degraded, but the degradation of WP40 was the fastest. It is well known that the degradation rate of the bone regeneration material should be moderate, which results in its matching the regeneration of new bone tissue at the implant site..$^{29,30}$ In this work, the weight loss ratio of WP0 was $43 \%$ at 12 weeks. However, with the increase in the m-MS content, the degradation rate of the composites accelerated, and at 12 weeks, the weight loss rates of the WP20 and WP40 were $46 \%$ and 56\%, respectively. Studies have shown that the degradation of mesoporous materials was faster than non-mesoporous materials, and the degradability of the ordered mesoporous materials was of great significance for their applications in biomedical materials. ${ }^{31-33}$ Thus, this study further demonstrated that m-MS played a dominant role in the degradation of the composites because of the ordered pore structure, high specific surface area and high pore volume of m-MS.

Fig. $5 \mathrm{~b}$ exhibits the $\mathrm{pH}$ value changes of the solution after the samples were soaked in Tris- $\mathrm{HCl}$ for different times. During the immersion time, the $\mathrm{pH}$ value of WP0 continuously 

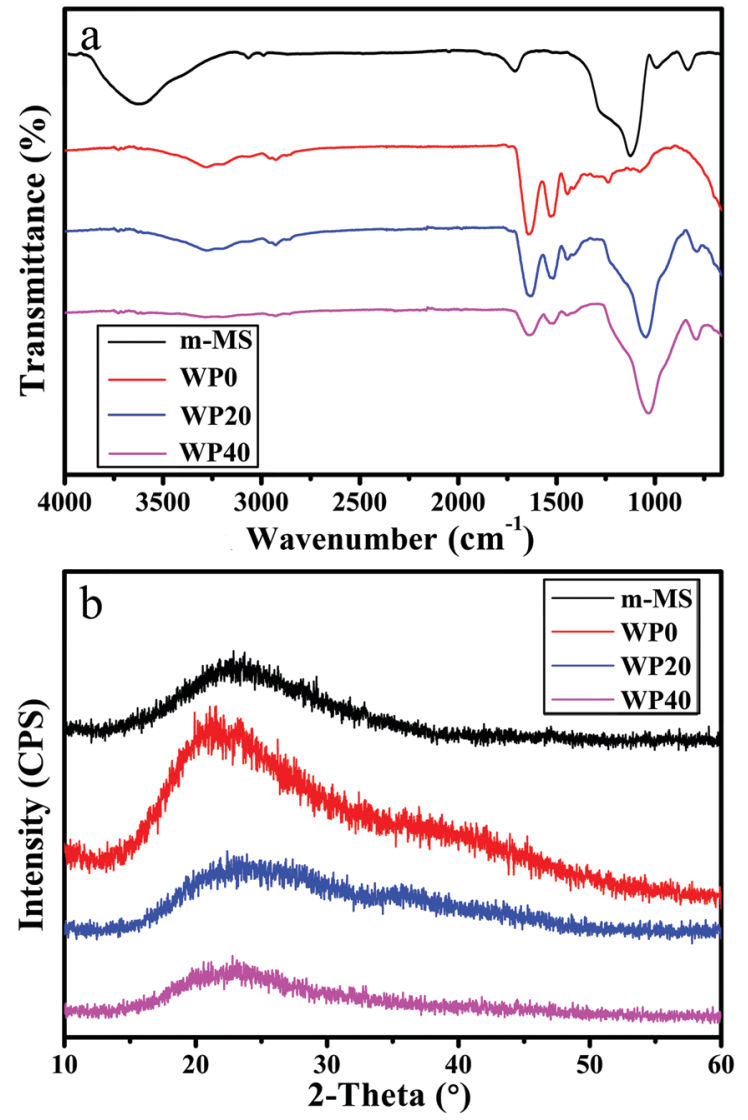

Fig. 2 FTIR spectra (a) and X-ray diffraction patterns (b) of the samples.

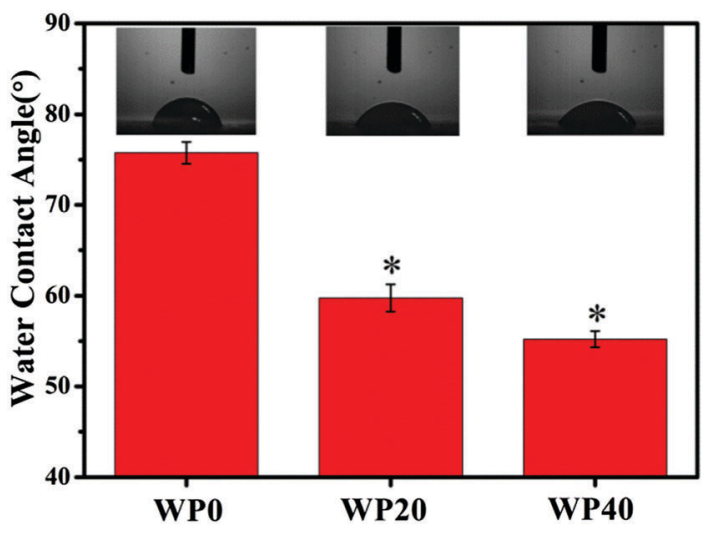

Fig. 3 Water contact-angles of WPO, WP20 and WP40. decreased during the degradation period (from 7.4 to 6.8), indicating that acidic products were produced during WP degradation. In contrast, after a 4 week immersion the $\mathrm{pH}$ for WP40 increased to 7.61, whereas the pH for WP20 declined to 7.29 and then increased to 7.49. Additionally, after a 12 week immersion in the Tris-HCl solution, the pH for WP20 declined to 6.94, while the WP40 decreased to 7.10 and was finally stable. The reason for this trend was that a large amount of m-MS on the surface of WP40 degraded and released $\mathrm{Mg}^{2+}$ and $\mathrm{SiO}_{4}{ }^{4-}$ in the early days of immersion, which led to a weak alkaline environment. ${ }^{34}$ With the degradation of WP40, the degradation products of WP were much more than m-MS, so the solution $\mathrm{pH}$ decreased slightly. The $\mathrm{pH}$ variation in WP40 was in complete conformity with the tissue microenvironment in the human body, which could promote cell proliferation and differentiation. ${ }^{35}$ Therefore, the addition of increasing content of m-MS could prevent the $\mathrm{pH}$ from decreasing when implanted in vivo.

\subsection{Apatite-formation on m-MS/WP composites}

Fig. 6 shows SEM images of WP0, WP20 and WP40 before and after soaking in SBF for 7 days. It can be found that the surface of WP0 was smooth and homogeneous before soaking in SBF; however, some microcracks appeared on the WP0 surface, which might be due to the sample processing (Fig. 6a). With the increasing content of m-MS (WP20, WP40), the composite surfaces became coarser, and some small particles were found on the surfaces (Fig. 6c and e). The ability of apatite formation and the quantity of the forming apatite are very important for the binding of implant materials to living bone tissue, and this can be evaluated in SBF solution in vitro. ${ }^{36,37}$ This research showed that, after soaking for 7 days, only a very small amount of irregular particles formed on the surface of WP0 (Fig. 6b). In contrast, the new apatites with about a $2 \mu \mathrm{m}$ diameter and microsphere morphology formed on the surface of WP20 (Fig. 6d). However, it can be seen that the microspheres aggregated on the surface of WP40 were much denser than WP20 (Fig. 6f), and the microspheres were apatite, which was shown by the following XRD and EDS analysis. The present studies revealed that $\mathrm{m}$-MS has received much attention for its unique apatite formation ability, as well as the bioactive properties, ${ }^{24,25,38}$ so the apatite formed on the surface of composite should be attributed to the presence of m-MS within the materials.

Fig. 7 reveals changes in the $\mathrm{Ca}, \mathrm{Mg}, \mathrm{P}$ and $\mathrm{Si}$ ion concentrations in SBF after WP40 soaking for different times (1, 3, 5, 7 and 14 days). $\mathrm{Mg}$ ions and $\mathrm{Si}$ ions had an increasing trend during the
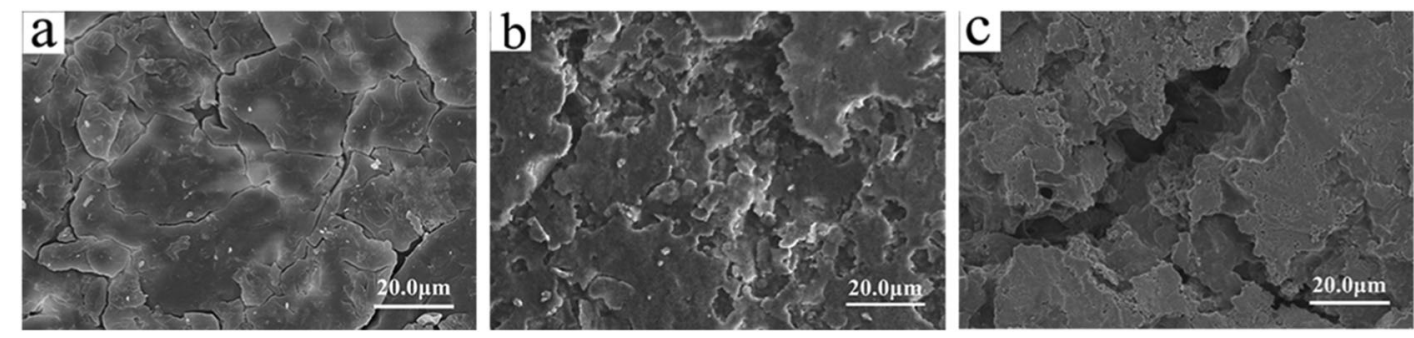

Fig. 4 SEM images of the surface morphology of WPO (a), WP2O (b) and WP40 (c) after immersion in Tris- $\mathrm{HCl}$ for 3 weeks. 

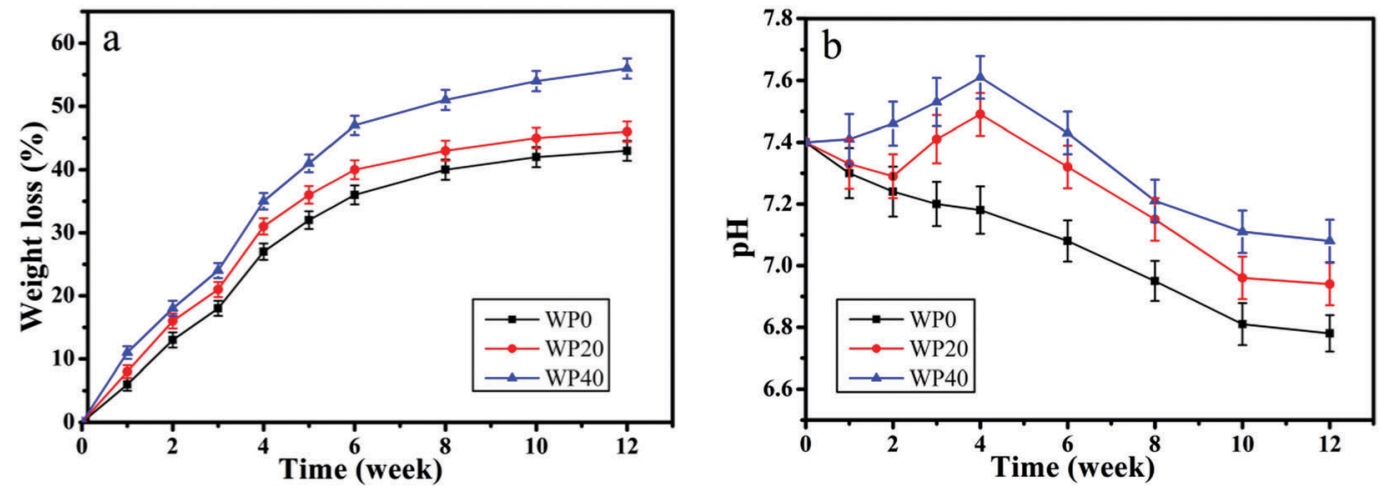

Fig. 5 Weight loss (a) of WPO, WP2O and WP40 and pH change (b) of the solution after immersion in the Tris- $\mathrm{HCl}$ solution for different time periods.
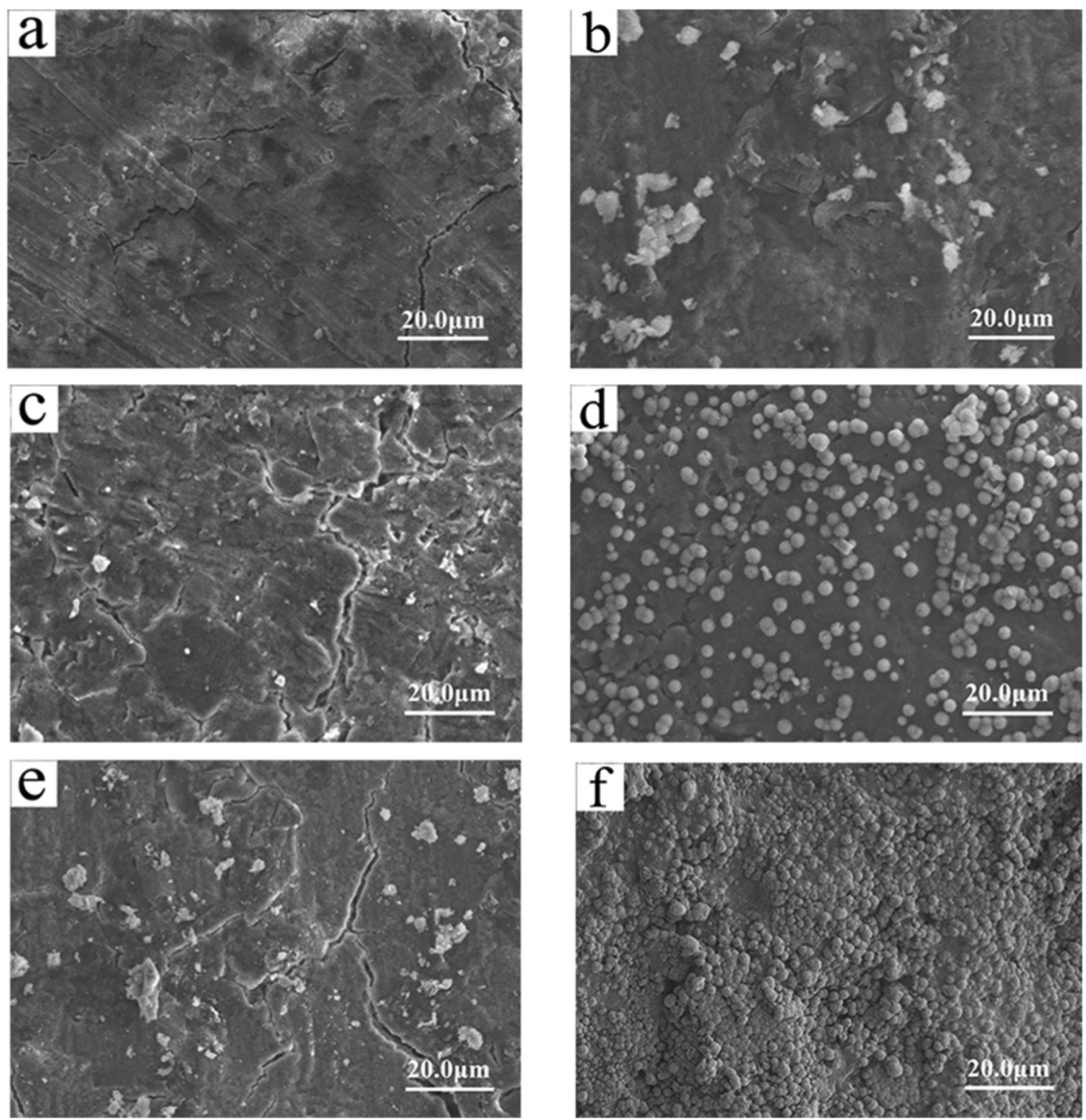

Fig. 6 SEM images of the surface morphology of the specimens with various m-MS content before (a: WP0, c: WP20 and e: WP40) and after soaking in SBF solution for 7 days (b: WPO, d: WP20 and f: WP40).

mineralization process. In contrast, $\mathrm{Ca}$ ions and $\mathrm{P}$ ions significantly declined. In addition, the reduction in the total amount of $\mathrm{Ca}$ ions was greater than that of $\mathrm{P}$, which might result in the formation of the apatite layer. From the changes in the $\mathrm{Ca}, \mathrm{Si}$ and $\mathrm{P}$ ion concentrations in SBF, the mechanism of the apatite mineralization was more m-MS in WP40 than WP20 to form a 


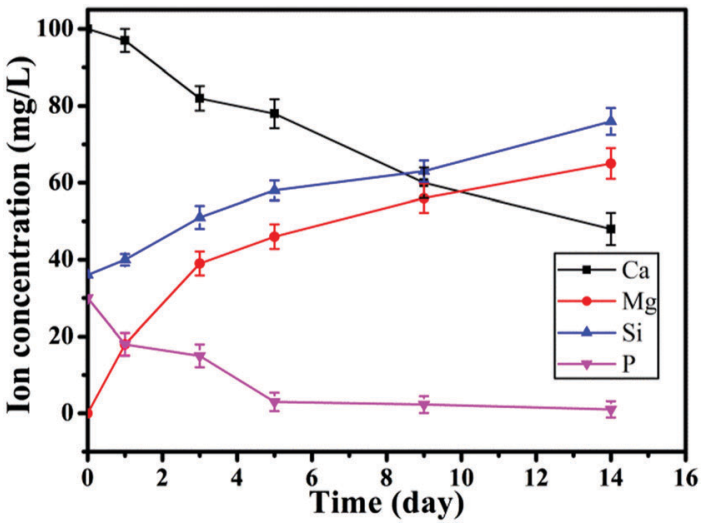

Fig. 7 Changes of ion concentrations in SBF solution after immersion of WP40 for different periods.

Si-rich layer, which then induced the deposition of $\mathrm{Ca}$ ions and $\mathrm{P}$ ions following nucleation and further forming apatite. Therefore, the results suggested that WP40 with a significantly improved bioactivity was expected to form a chemical bond between bone tissue and material through the rich apatite layer when implanted in vivo.

To further determine apatite formation on the WP20 and WP40 surfaces, the XRD of the samples after soaking in SBF for 7 days are shown in Fig. 8a. The diffraction peaks at approximately $2 \theta=25.17^{\circ}, 42.68^{\circ}, 44.40^{\circ}$ and $55.42^{\circ}$ were attributed to the characteristic peaks of apatite on the surface of the samples. ${ }^{39,40}$ Fig. 8b (inset) shows the higher magnification of WP40 after soaking in SBF for 7 days. The surface was fully covered by a new layer, which was made up of regular microsphere crystals with the typical morphology of apatite. The EDS of WP40 after soaking in SBF for 7 days was to further used to determine the presence of $\mathrm{P}$ and Ca signals as the main components of the microspheres formed on the material surface. The results revealed the mole ratio of $\mathrm{Ca}$ to $\mathrm{P}$ was approximately 1.63, which was close to that of stoichiometric hydroxyapatite $(\mathrm{Ca} / \mathrm{P}$ : 1.67), ${ }^{41}$ confirming that the formation of the regular microsphere crystals on the WP40 surface was the apatite layer.

\subsection{Cell morphology of composites}

Bioactive biomaterials need to have good compatibility with cells and even stimulate cell growth. Cell adhesion and spreading is an important step for the later cell proliferation and differentiation. ${ }^{42}$ Fig. 9 shows the CLSM images of the cytoskeletons stained by DAPI and FITC after MC3T3-E1 cells cultured on WP0, WP20 and WP40 for 3 days. DAPI staining showed a single, round cell nucleus for each cell (stained in blue), and FITC staining showed cytoplasmic for each cell in all cases (stained in green). It can be seen that the spreading morphology of cells in response to all materials occurred, indicating that the materials had no toxic effect on the cells. Previous studies have shown that m-MS stimulated the cell proliferation and osteogenic differentiation..$^{25,43}$ In this study, Fig. 9b and c clearly shows that the presence of m-MS increased cell attachment on the composites. More MC3T3-E1 cells spread and anchored on the
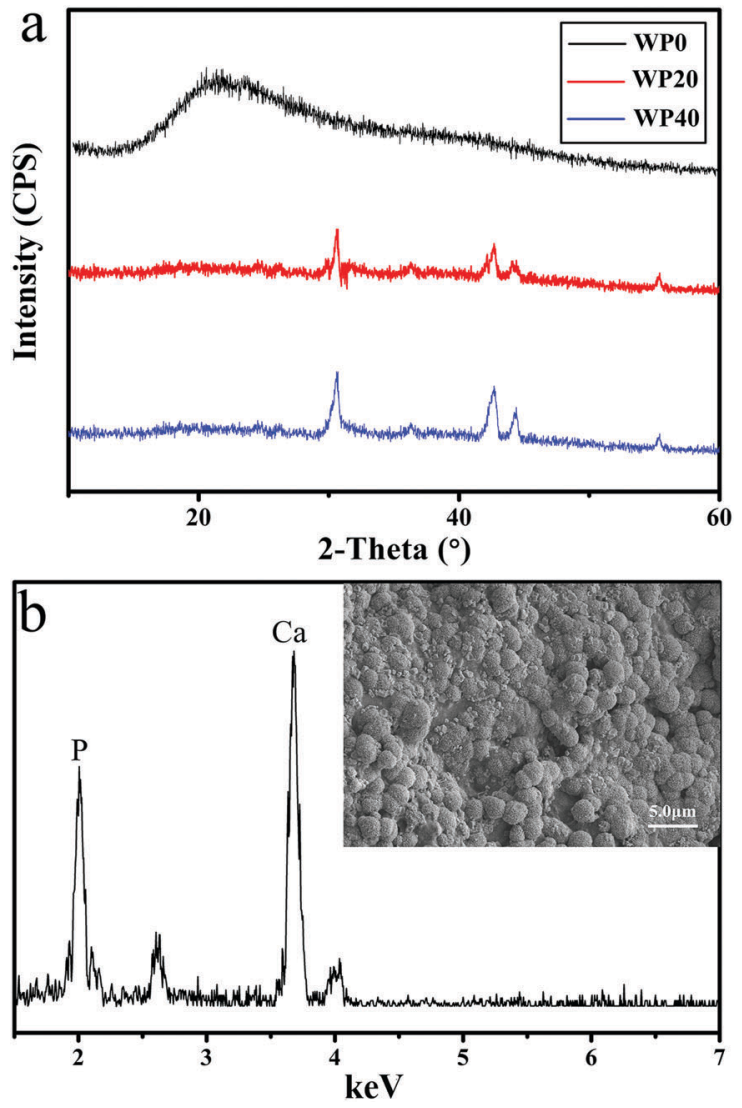

Fig. 8 XRD (a) of the samples immersed in SBF for 7 days. Black dots represent the peaks of apatite. The EDS and SEM at a higher magnification (inset) (b) of WP40 after soaking in SBF for 7 days.

WP40 surface (covered with multilayer of cells), indicating better cytocompatibility of WP40 than the others.

\subsection{Cell proliferation on $\mathrm{m}-\mathrm{MS} / \mathrm{WP}$ composites}

Fig. 10 shows the O.D. values of MC3T3-E1 cells cultured on WP0, WP20 and WP40 at 1, 3 and 5 days. A conspicuous increase in the cell proliferation was observed in all materials with the increasing culture time, which could be considered the good cytocompatibility of the materials. At day 1, there were slight differences in the O.D. values among the different groups of samples, but at day 3 and day 5, the O.D. value for the WP40 was significantly higher than WP0 and WP20. The MTT results proved that the proliferation of cells on the composites was obviously enhanced by the increase in the m-MS content, suggesting that incorporation of m-MS into WP could significantly improve cell proliferation. The hydrophilic surface of WP40 was favorable for cell attachment and spreading. Further, the rich $\mathrm{Mg}^{2+}$ ions of the WP40 played the role of ligands for osteoblast favoured protein adsorption due to positive electrostatic attraction, which was beneficial for better cytocompatibility.

\subsection{ALP activity of cells on composites}

ALP activity is known to be an early marker for functionality and differentiation of osteoblasts during in vitro experiments. ${ }^{44,45}$ ALP hydrolyzes the ester phosphates to orthophosphate 

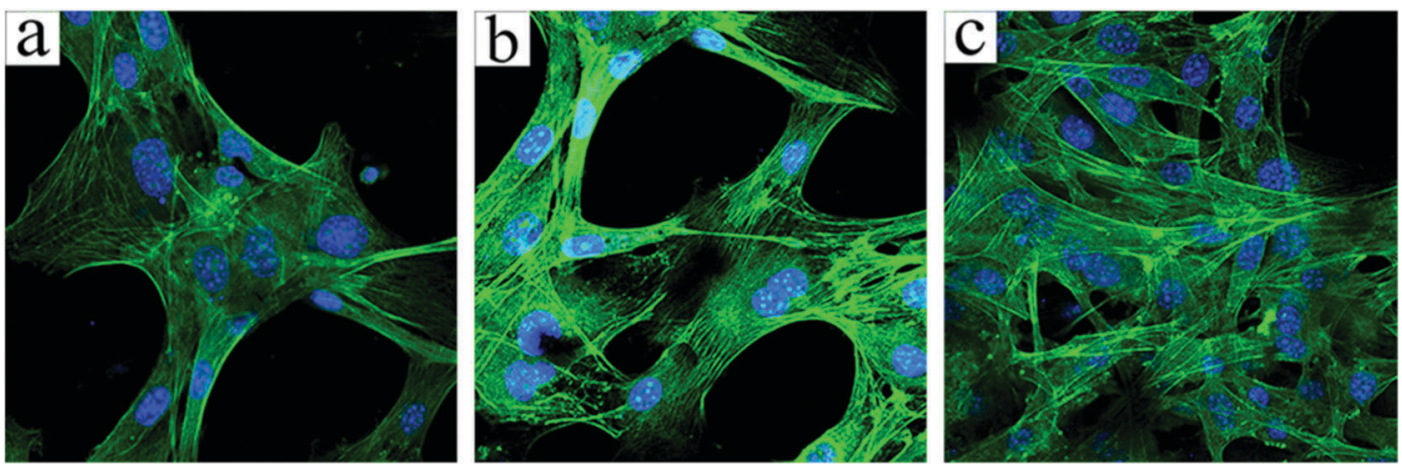

Fig. 9 CLSM images of cytoskeletons stained by DAPI and FITC after being cultured on WPO (a), WP20 (b) and WP40 (c) for 3 days.

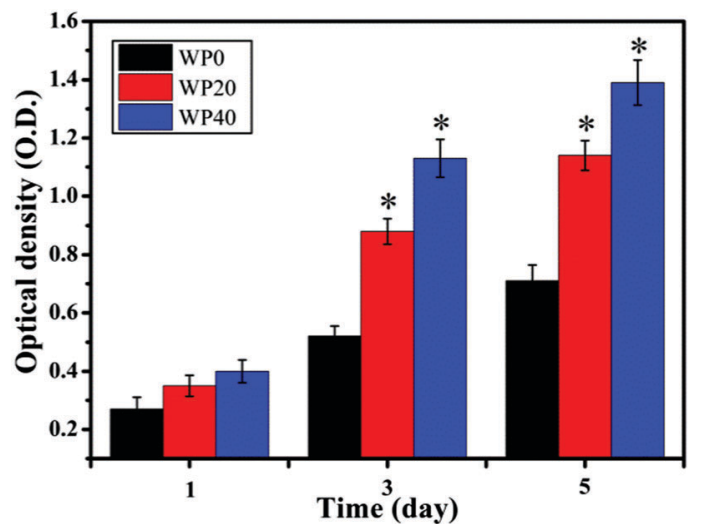

Fig. 10 The proliferation of MC3T3-E1 cells on the surface of WPO, WP20 and WP40 with different cultivating times.

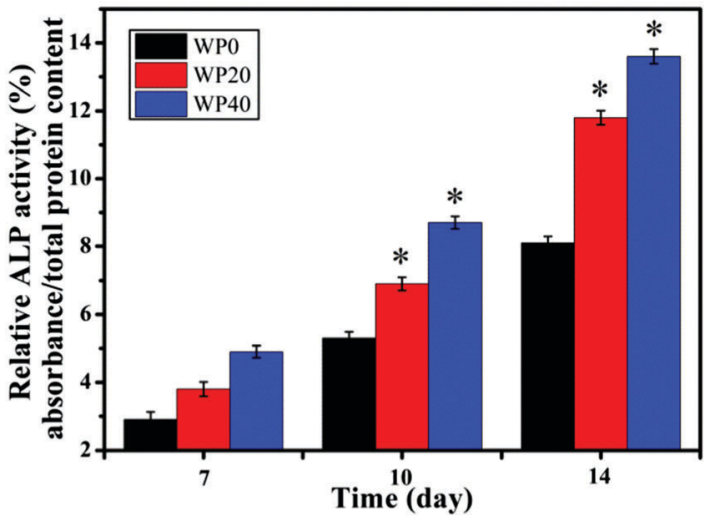

Fig. 11 ALP activity of MT3T3-E1 cells after cultivating for 7, 10 and 14 days on WPO, WP20 and WP40.

$\mathrm{PO}_{4}{ }^{3-}$, which subsequently incorporate into calcium phosphate minerals. ${ }^{46}$ Fig. 11 shows ALP activity of MC3T3-E1 cells after cultivating on WP0, WP20 and WP40 for 7, 10 and 14 days. After day 7 and day 10, the ALP activity of the cells grown on WP40 was slightly higher than that on WP0 and WP20. In addition, it was found that, at day 14, the ALP activity of WP40 was significantly higher than that on WP20 and WP0. The results showed that the ALP expression levels of the cells on the samples increased with the m-MS content. Several studies have confirmed that the $\mathrm{Mg}$ and $\mathrm{Si}$ ions could stimulate osteoblast differentiation, and $\mathrm{Si}$ ions could also improve the ability of both osteoblasts and fibroblasts to produce collagen type I, which could promote cell differentiation. ${ }^{4-49}$ Therefore, in this study, the increased ALP activity probably resulted from m-MS, indicating that the $\mathrm{Mg}$ and $\mathrm{Si}$ ions of m-MS might be responsible for stimulating cell differentiation. In conclusion, the WP40 composite with good cytocompatibility might have good biofunctions to stimulate bone repair and regeneration.

\section{Conclusions}

This study describes a new composite based on wheat protein and mesoporous magnesium silicate for potential bone tissue regeneration. The obtained results demonstrated that the addition of m-MS into WP improved the surface hydrophilicity of the composites. Meanwhile, the incorporation of m-MS into WP was beneficial for improving the degradability and apatite formation ability of the m-MS/WP composites. During degradation, the WP40 revealed the ability to induce a weak alkaline environment and prevented the $\mathrm{pH}$ from dropping, which might be associated with the m-MS. In addition, more apatites were formed on the surface of the WP40 composite after immersion in SBF for 7 days than on WP0 and WP20, implying that the m-MS improved the bioactivity of the composite. In the cell culture experiments, the addition of m-MS into WP could promote cell attachment, proliferation and differentiation. The whole study demonstrated that WP40 had excellent biocompatibility, degradability, cytocompatibility and osteogenesis, which might be a new biomaterial for bone tissue regeneration.

\section{Acknowledgements}

This study was supported by grants from the National Natural Science Foundation of China $(81271705,81572194)$, the National High Technology Research \& Development Program of China (863 Program) (no. 2014AA021202), the Major International Joint Research Project between China and Korea (81461148033), and the National Research Foundation of Korea (NRF) Grant (NRF2014K2A2A7066637), and Zhejiang Provinical Natural Science Foundation of China (LY15E020001), Medical Scientific Research Foundation of Zhejiang Province (2014PYA021). 


\section{Notes and references}

1 N. Ninan, M. Muthiah, I. K. Park, T. W. Wong, S. Thomas and Y. Grohens, Polym. Rev., 2015, 55, 453-490.

2 A. Sionkowska, Prog. Polym. Sci., 2011, 36, 1254-1276.

3 H. F. Ko, C. Sfeir and P. N. Kumta, Philos. Trans. R. Soc., A, 2010, 368, 1981-1997.

4 S. Venkatraman, F. Boey and L. L. Lao, Prog. Polym. Sci., 2008, 33, 853-874.

5 M. Swetha, K. Sahithi, A. Moorthi, N. Srinivasan, K. Ramasamy and N. Selvamurugan, Int. J. Biol. Macromol., 2010, 47, 1-4.

6 X. Q. Zhang, Y. Gozukara, P. Sangwan, D. C. Gao and S. Bateman, Polym. Degrad. Stab., 2010, 95, 2309-2317.

7 S. Barak, D. Mudgil and B. S. Khatkar, Crit. Rev. Food Sci. Nutr., 2015, 55, 357-368.

8 X. Zhang, M. D. Do and A. Bilyk, Biomacromolecules, 2007, 8, 1881-1889.

9 F. Muneer, M. Andersson, K. Koch, C. Menzel, M. S. Hedenqvist, M. Gallstedt, T. S. Plivelic and R. Kuktaite, Biomacromolecules, 2015, 16, 695-705.

10 L. Liao, C. Y. Qiu, T. X. Liu, M. M. Zhao, J. Y. Ren and H. F. Zhao, J. Cereal Sci., 2010, 52, 395-403.

11 L. Liao, Q. Wang and M. M. Zhao, J. Sci. Food Agric., 2012, 92, 1865-1873.

12 Y. L. Naito, N. V. Honch, Y. Chikaraishi, N. Ohkouchi and M. Yoneda, Am. J. Phys. Anthropol., 2010, 143, 31-40.

13 N. Z. Knezevic and J. O. Durand, Nanoscale, 2015, 7, 2199-2209.

14 Y. C. Chiang, H. P. Lin, H. H. Chang, Y. W. Cheng, H. Y. Tang, W. C. Yen, P. Y. Lin, K. W. Chang and C. P. Lin, ACS Nano, 2014, 8, 12502-12531.

15 F. Y. Hsu, R. C. Weng, H. M. Lin, Y. H. Lin, M. R. Lu, J. L. Yu and H. W. Hsu, Microporous Mesoporous Mater., 2015, 212, 56-65.

16 M. C. Shi, Y. H. Zhou, J. Shao, Z. T. Chen, B. T. Song, J. Chang, C. T. Wu and Y. Xiao, Acta Biomater., 2015, 21, 178-189.

17 J. Zhang, X. Y. Ma, D. Lin, H. S. Shi, Y. Yuan, W. Tang, H. J. Zhou, H. Guo, J. C. Qian and C. S. Liu, Biomaterials, 2015, 53, 251-264.

18 Y. J. Chen, Z. G. Xu, C. Smith and J. Sankar, Acta Biomater., 2014, 10, 4561-4573.

19 S. V. Dorozhkin, Acta Biomater., 2014, 10, 2919-2934.

20 T. S. N. S. Narayanan, I. S. Park and M. H. Lee, Prog. Mater. Sci., 2014, 60, 1-71.

21 C. L. Dai, H. Guo, J. X. Lu, J. L. Shi, J. Wei and C. S. Liu, Biomaterials, 2011, 32, 8506-8517.

22 E. Babaie, Y. F. Ren and S. B. Bhaduri, J. Mater. Res., 2016, 31, 995-1003.

23 M. Afshar-Mohajer, A. Yaghoubi, S. Ramesh, A. R. Bushroa, K. M. C. Chin, C. C. Tin and W. S. Chiu, Appl. Surf. Sci., 2014, 307, 1-6.

24 M. Diba, O. M. Goudouri, F. Tapia and A. R. Boccaccini, Curr. Opin. Solid State Mater. Sci., 2014, 18, 147-167.

25 Y. F. Niu, W. Dong, H. Guo, Y. H. Deng, L. P. Guo, X. F. An, D. W. He, J. Wei and M. Li, Int. J. Nanomed., 2014, 9, 2665-2675.

26 S. Tunc, H. Angellier, Y. Cahyana, P. Chalier, N. Gontard and E. Gastaldi, J. Membr. Sci., 2007, 289, 159-168.
27 Z. Y. Cheng and S. H. Teoh, Biomaterials, 2004, 25, 1991-2001.

28 J. Yang, J. Z. Bei and S. G. Wang, Biomaterials, 2002, 23, 2607-2614.

29 T. Jiang, S. P. Nukacarapu, M. Deng, E. Jabbarzadeh, M. D. Kofron, S. B. Doty, W. I. Abdel-Fattah and C. T. Laurencin., Acta Biomater., 2010, 6, 3457-3470.

30 J. Patterson, R. Siew, S. W. Herring, A. S. P. Lin, R. Guldberg and P. S. Stayton, Biomaterials, 2010, 31, 6772-6781.

31 X. H. Hao, X. X. Hu, C. M. Zhang, S. Z. Chen, Z. H. Li, X. J. Yang, H. F. Liu, G. Jia, D. D. Liu, K. Ge, X. J. Liang and J. C. Zhang, ACS Nano, 2015, 9, 9614-9625.

32 Y. F. Niu, L. P. Guo, J. Liu, H. X. Shen, J. C. Su, X. F. An, B. Q. Yu, J. Wei, J. W. Shin, G. Han, F. Ji and D. W. He, J. Mater. Chem. B, 2015, 3, 2962-2970.

33 J. X. Lu, J. Wei, Q. Gan, X. Lu, W. H. Song, Y. G. Yan, J. Ma, H. Guo, T. Q. Xiao and C. S. Liu, Microporous Mesoporous Mater., 2012, 163, 221-228.

34 C. T. Wu, J. Chang and W. Fan, J. Mater. Chem., 2012, 22, 16801-16809.

35 S. C. Tao, Y. S. Gao, H. Y. Zhu, J. H. Yin, Y. X. Chen, Y. L. Zhang, S. C. Guo and C. Q. Zhang, Sci. Rep., 2016, 6, 26835.

36 M. S. Kang, J. H. Kim, R. K. Shingh, J. H. Jang and H. W. Kim, Acta Biomater., 2015, 16, 103-116.

37 S. A. Yavari, J. van der Stok, Y. C. Chai, R. Wauthle, Z. T. Birgani, P. Habibovic, M. Mulier, J. Schrooten, H. Wauthle and A. A. Zadpoor, Biomaterials, 2014, 35, 6172-6181.

38 Z. Y. Wu, T. T. Tang, H. Guo, S. C. Tang, Y. F. Niu, J. Zhang, W. J. Zhang, R. Ma, J. C. Su and C. S. Liu, Colloids Surf., B, 2014, 120, 38-46.

39 Z. Y. Li, W. M. Lam, C. Yang, B. Xu, G. X. Ni, S. A. Abbah, K. M. C. Cheung, K. D. K. Luk and W. W. Lu, Biomaterials, 2007, 28, 1452-1460.

40 S. A. Hutchens, R. S. Benson, B. R. Evans, H. M. O'Neill and C. J. Rawn, Biomaterials, 2006, 27, 4661-4670.

41 S. C. G. Leeuwenburgh, J. G. C. Wolke, J. Schoonman and J. A. Jansen, Biomaterials, 2004, 25, 641-649.

42 E. Tejeda-Montes, A. Klymov., M. R. Nejanik, M. Alonso, J. C. Rodriguez-Cabello, X. F. Walboomers and A. Mata, Biomaterials, 2014, 35, 8339-8347.

43 D. W. He, W. Dong, S. C. Tang, J. Wei, Z. H. Liu, X. J. Gu, M. Li, H. Guo and Y. F. Niu, J. Mater. Sci.: Mater. Med., 2014, 25, 1415-1424.

44 M. C. Xu, D. Zhai, J. Chang and C. T. Wu, Acta Biomater., 2014, 10, 463-476.

45 W. J. Zhang, G. C. Wang, Y. Liu, X. B. Zhao, D. H. Zou, C. Zhu, Y. Q. Jin, Q. F. Huang, J. Sun and X. Y. Liu, Biomaterials, 2013, 34, 3184-3195.

46 S. J. Dong, J. Y. Sun, Y. D. Li, J. Li, W. G. Cui and B. Li, Mater. Sci. Eng., C, 2014, 35, 426-433.

47 L. L. Wu, F. Feyerabend, A. F. Schilling, R. Willumeit-Romer and B. J. C. Luthringer, Acta Biomater, 2015, 27, 294-304.

48 H. Y. Li, K. Xue, N. Kong, K. Liu and J. Chang, Biomaterials, 2014, 35, 3803-3818.

49 X. X. Zhang, C. Zhang, W. Xu, B. Zhong, F. Lin, J. Zhang, Q. X. Wang, J. J. Wei and Y. Zhang, Int. J. Nanomed., 2015, 10, 6699-6708. 